\title{
Intravascular bone marrow accumulation in persistent polyclonal lymphocytosis: a misleading feature for B-cell neoplasm
}

\author{
Pierre Feugier ${ }^{1}$, Anne Kennel de March $^{2}$, Jean F Lesesve ${ }^{3}$, Nathalie Monhoven ${ }^{4}$, \\ Véronique Dorvaux ${ }^{5}$, Françoise Braun ${ }^{5}$, Marie J Grégoire ${ }^{6}$, Philippe Jonveaux ${ }^{6}$, \\ Pierre Lederlin ${ }^{1}$, Marie C Béné ${ }^{2}$ and Eric Labouyrie ${ }^{4}$
}

${ }^{1}$ Department of Hematology-Internal Medicine; ${ }^{2}$ Department of Immunology; ${ }^{3}$ Department of Cytology;

${ }^{4}$ Department of Pathology, University Hospital of Nancy, France; ${ }^{5}$ Department of Hematology-Internal

Medicine, Hospital of Metz-Thionville, France and ${ }^{6}$ Department of Genetics, University Hospital of Nancy,

France

\begin{abstract}
Persistent polyclonal B-cell lymphocytosis is usually reported in young smoking women. Whether this syndrome represents a premalignant or benign disease remains unclear. Indeed, because of the association of $\mathrm{Bcl}-2 / \mathrm{lgH}$ rearrangement and cytogenetic abnormalities, such cases may be misdiagnosed as the leukemic phase of a non-Hodgkin's lymphoma. We report eight new cases of persistent polyclonal B-cell lymphocytosis, which displayed a misleading bone marrow histological pattern, that is, intravascular B-cell infiltrate, constantly associated with Bcl-2 immunohistostaining, as seen in some lymphoma. We also show the absence or low expression of adhesion molecules on persistent polyclonal B-cell lymphocytes, suggesting that migration abnormalities might lead to bone marrow and peripheral blood accumulation. Although most cases presented multiple Bcl-2/lgH gene rearrangements and appeared to be polyclonal, oligoclonal expansion was identified in one out of eight patients, yet was not associated with clinical aggressiveness. The occasional reports of oligoclonal IgH and $\mathrm{Bcl}-2 / \mathrm{lgH}$ rearrangements in this disorder suggest that polyclonal expansion may be followed by the emergence of a predominant clone. However, the benign clinical course and lack of biological evolution in most cases imply that it is mandatory to distinguish this disorder from other malignant lymphoproliferations, so that unnecessary aggressive therapy can be avoided.

Modern Pathology (2004) 17, 1087-1096, advance online publication, 14 May 2004; doi:10.1038/modpathol.3800156
\end{abstract}

Keywords: polyclonal B-cell lymphocytosis; bone marrow; intravascular

Persistent lymphocytosis in adults is usually clonal and related to malignant lymphoproliferative disease, most commonly of B-cell origin, including chronic lymphocytic leukemia (CLL), prolymphocytic leukemia, splenic marginal zone lymphoma (SMZL) with or without villous lymphocytes, hairy-cell leukemia and leukemic phase of follicular lymphoma or mantle cell lymphoma. ${ }^{1}$ By contrast, polyclonal persistent lymphocytosis is unusual and observed in such conditions as hyposplenic states, ${ }^{2}$ rheumatoid arthritis, ${ }^{3}$ Gaucher's disease ${ }^{4}$ or idiopathic persistent polyclonal B-cell lymphocytosis (PPBL). This entity, also called B-cell lymphocytosis with binucleated lymphocytes, was

Correspondence: Dr E Labouyrie, MD, PhD, Service de Pathologie, Hôpitaux de Brabois Adultes, Allée du Morvan, 54500 Vandoeuvre les Nancy, France.

E-mail: e.labouyrie@chu-nancy.fr

Received 15 March 2004; revised 8 April 2004; accepted 9 April 2004; published online 14 May 2004 initially reported by Gordon et $a l^{5}$ in young to middle-aged women, usually smokers. Such patients present with a moderate tumoral syndrome, isolated splenomegaly and a mild persistent polyclonal binucleated lymphocytosis of B-cell origin. Immunophenotyping evidences the expression of CD19 and surface IgM, with a normal $\kappa / \lambda$ ratio indicating the absence of clonality. A genetic predisposition is suggested by the close association of this disorder with the HLA-DR7 allele, by the diagnosis of PPBL in monozygotic twins, as well as by reports of PPBL in three members of the same generation and multiple Bcl-2/IgH gene rearrangements among first-degree relatives. ${ }^{6-8}$ Although most patients present with a PPBL, demonstrated by immunophenotyping and genotype analysis, a monoclonal lymphoid profile has been reported in some PPBL patients as determined by analysis of immunoglobulins heavy chain genes ${ }^{9,10}$ or chromosomal studies. ${ }^{11}$ 
Whether this syndrome represents a premalignant or benign disease however remains unclear, although long-term follow-up suggests that whenever malignant progression occurs, it is after a long latency. The PPBL syndrome itself presents with many features that may suggest malignancy to the unwary, with morphologically peculiar peripheral blood lymphocytes, splenomegaly, lymphoid aggregates in the bone marrow (BM) and FMC7 expression. Such cases, especially because of the association of Bcl-2/IgH rearrangements and cytogenetic abnormalities, thus may be misdiagnosed as the leukemic expression of a non-Hodgkin's lymphoma. Indeed, several patients have unnecessarily received chemotherapy before the diagnosis of PPBL was clearly established. ${ }^{12}$

In this context, it may be useful to perform a BM biopsy in order to exclude the lymphoma hypothesis, yet the pattern observed in such samples still may be misleading, as reported here in a new series of eight patients. BM histology showed features suggestive of SMZL, with accumulation of Bcl2 + B-lymphocytes in BM sinuses. Extensive exploration of these patients also allowed to observe an abnormal expression of adhesion molecules on peripheral lymphocytes, that could partially explain the pathophysiology of the disorder.

\section{Patients and methods}

Eight patients (seven female and one male) were seen repeatedly at the out-patient clinics of Nancy and Metz-Thionville hospitals between 1994 and 2003. PPBL diagnosis was based on persistent lymphocytosis over $4 \mathrm{G} / \mathrm{L}$ and the presence of binucleated cells on peripheral blood smears. Complete white blood cell (WBC) counts were performed using Bayer (Tarrytown, New York, NY, USA) automated analyzers (Technicon $\mathrm{H} 2$ and Advia 120). Blood smears were stained according to the May-Grünwald-Giemsa's technique, and 200 cells were counted to establish a differential.

\section{BM Cytology and Histology}

BM biopsies and smears were performed in seven out of eight patients, from samples collected in the posterior superior iliac bone using a Jamshidi needle. BM smears were stained with May-Grünwald-Giemsa. BM biopsies were fixed in Bouin's fixative for $12 \mathrm{~h}$, decalcified in ethylene diamine tetraacetic acid (EDTA) for $2 \mathrm{~h}$, dehydrated in ethanol and paraffin embedded. Sections $(5 \mu \mathrm{m})$ were cut with a rotary microtome and routinely stained with hematein-eosin-saffron (HES), Giemsa and Gordon-Sweet silver stains. After a heat-induced epitope retrieval step by microwave heating, immunostaining was carried out with a streptavidinbiotin-peroxidase method with NovaRED substrate (Vector-Biovalley, Marne-La-Vallée, France). Endo- genous peroxidase activity was blocked with $0.3 \%$ $\mathrm{H}_{2} \mathrm{O}_{2}$ in methanol for $30 \mathrm{~min}$. Incubations were performed overnight at $+4^{\circ} \mathrm{C}$ with one of the following monoclonal antibodies (MoAbs): CD45 (pan-leukocyte), CD20 (L26), CD79a, CD3, CD5, CD23, CD43 or bcl2 (Dako, Glostrup, Denmark).

\section{In Situ Hybridization for EBV EBER RNA}

In situ hybridization for the detection of EpsteinBarr virsus (EBV)-infected cells was performed on $5 \mu \mathrm{m}$ sections of Bouin's fixed BM biopsies, with fluorescein isothiocyanate (FITC)-labeled oligonucleotides directed against EBV encoded small RNAs (EBER) EBER1 and EBER2 RNAs (Dako). In situ hybridization was achieved for $2 \mathrm{~h}$ at $55^{\circ} \mathrm{C}$, after a $10 \mathrm{~min}$ treatment with proteinase $\mathrm{K}$ at $37^{\circ} \mathrm{C}$, and detection was performed with the appropriate primary antibodies and an alkaline phosphatase/ antialkaline phosphatase (APAAP) technique. Nitroblue tetrazolium chloride/Bromo chloro indolyl phosphate (NBT/BCIP) substrate (Roche, Meylan, France) was used for color development of EBERs hybridization.

\section{Immunophenotyping}

Peripheral blood mononuclear cells were separated by density-gradient centrifugation and immunophenotyping was performed by direct or indirect immunofluorescence with a panel of MoAbs: CD5, CD19, CD20 from Beckman Coulter (Miami, FL, USA), CD22, CD23 from Becton-Dickinson (Mountain View, CA, USA) and CD38, CD43, CD79b, FMC7 from Dako. For surface immunoglobulins (SIgs) detection, anti- $\kappa$ and anti- $\lambda$ polyclonal or monoclonal antibodies (Dako) were used. Additionally, expression of the adhesion molecules CD29, CD49d, CD31, CD11a/CD18 or LFA-1, CD54, CD103, CD62L, CD62P and CD62E (Beckman Coulter) was investigated. Immunofluorescence analysis was performed by flow cytometry using a Facscalibur analyzer (Becton-Dickinson) or an EPICS XLMCL analyzer (Beckman Coulter). For adhesion molecules, calibration of the flow cytometer was performed with immunobrite beads (Beckman Coulter), allowing to express the fluorescence intensity in molecular equivalents of surface fluorescence (MESF). These data were compared to normal values established with the same method and the same flow cytometer in the Immunology laboratory. ${ }^{13}$

\section{Intracytoplasmic Labeling}

Intracytoplasmic or nuclear labeling was performed on cytocentrifuge smears prepared with a Cytospin 2 (Shandon, Runcorn, UK) with $5 \times 10^{4}$ cells. The smears were air dried, fixed in cold ethanol for $5 \mathrm{~min}$, rehydrated in PBS for $5 \mathrm{~min}$ and incubated for 
$30 \mathrm{~min}$ at room temperature in a moist chamber with FITC rabbit antisera to human IgG, IgA, IgM, $\kappa$ or $\lambda$ light chains (Dako), or MoAbs directed towards EBV antigens (MA, VCA, EBNA, Zebra; Argene, Varilhes, France) or Ki67 (Becton-Dickinson) a marker of cell proliferation. The slides were then washed three times in phosphate-buffered saline (PBS). Those stained with MoAbs were further incubated for 30 min with FITC rabbit anti-mouse antiserum (Dako). After the last series of washes in PBS, all slides were mounted in PBS/glycerol and examined in UV light microscopy (Olympus BH2-Olympus, Tokyo, Japan). Data were expressed as percentage of positive cells among all cytospun lymphocytes.

\section{Elispot}

Antibody-producing cells were investigated according to the isotype of Ig produced as described previously using the ELISA spot (ELISPOT) assay (13), allowing for the detection of spot-forming cells (SFC). Briefly, 96-well polyvinylidene fluoride (PVDF) bottom plates (Millipore, Bedford, MA, USA) were moistened with methanol, coated overnight at $4^{\circ} \mathrm{C}$ with rabbit antisera to human IgG, IgA or IgM (Dako) diluted 1:1000 in PBS and distributed as $100 \mu \mathrm{l} /$ well. After successive PBS washings, plates were blocked by incubation with $150 \mu \mathrm{l}$ of RPMI-1640 (Sigma, St Louis, MO, USA) supplemented with $5 \%$ defatted dry milk for $2 \mathrm{~h}$ at $+37^{\circ} \mathrm{C}$. Without further washing, plates were emptied, $10^{4}$ cells from lymphocyte suspensions were added to each well in quadruplicate and plates were incubated for $4 \mathrm{~h}$ at $+37^{\circ} \mathrm{C}$ and $6 \% \mathrm{CO}_{2}$ in a watersaturated atmosphere. The plates were washed by immersion four times in PBS and four times in PBS supplemented with $0.1 \%$ Tween 20 (Sigma) and thoroughly flicked to remove all liquid. Horseradish peroxidase-conjugated antibodies to human $\kappa$ and $\lambda$ light chains (Dako) diluted at $0.26 \mu \mathrm{g} / \mathrm{ml}$ in PBSTween were added to the wells and those placed at $+4^{\circ} \mathrm{C}$, overnight. After a new series of thorough washes of the wells, spots were developed using a solution of diaminobenzidin (Sigma) in Tris-HCl (Sigma) 0.1 M pH 7.2, and PBS supplemented with $\mathrm{H}_{2} \mathrm{O}_{2}$ (Gifrer Barbezat, Decines, France) and nickel chloride (Sigma). The reaction was stopped with distilled water. Spots were enumerated using an Olympus microscope, equipped with a special filter for white-light epi-illumination at a magnification of $\times 50$. Results were expressed as number of spots for $10^{6}$ cells.

\section{High-resolution Immunoblot}

Serum samples were diluted in $\mathrm{NaCl} 0.15 \mathrm{M}$,. 1:100 for IgG and light chains and 1:50 for IgA and IgM. For each dilution, $3 \mu \mathrm{l}$ were loaded in a $1 \%$ agarose gel (Paragon, Beckman Coulter, Fullerton, CA, USA), and electrophoresis carried on for $25 \mathrm{~min}$ at $100 \mathrm{v}$ in barbital $1.2 \%$ buffer. Proteins were then blotted by capillarity on a nitrocellulose sheet (Protran $0.2 \mu \mathrm{m}$, Schleicher \& Schuell GmbH, Dassel, Germany) for $15 \mathrm{~min}$. Unoccupied sites were saturated by incubation in defatted dry milk $5 \%$ in distilled water for $45 \mathrm{~min}$ at room temperature. Strips were then cut out, corresponding to the deposits, and incubated for $1 \mathrm{~h}$ at room temperature with one each of the following alkaline phosphatase conjugated antibodies, anti-IgG, IgA, IgM (PARIS, Compiègne, France) or unconjugated MoAbs directed to $\kappa$ or $\lambda$ light chains (Immunotech, Marseille, France) diluted in PBS-borine serum albumin (BSA) $2 \%$. For the latter, a second incubation was carried out with alkaline phosphatase-conjugated rabbit antimouse Ig antibody (Jackson ImmunoResearch Laboratories, West Grove, PA, USA). After a series of thorough washes, strips were incubated with NBT/ BCIP (Sigma Chemicals, St Louis, MO, USA). The colored reaction developing was stopped in distilled water.

\section{Cell Cycle Analysis}

In all, $50 \mu$ l aliquots of whole blood were used in six cases for cell cycle analysis using the DNAPrep reagents (Beckman Coulter) allowing cell permeabilization, RNA degradation and intercalation of propidium iodide (PI) in the DNA. Primary histograms were generated by gating the cells according to the surface and peak of the PI fluorescence signal, in order to avoid taking doublets into account. These histograms were then submitted to computerized calculation of the cell cycle using the polynomial analysis derived from the Dean and Jett ${ }^{14}$ model with the specific software Multi-Cycle AV (Phoenix, Flow Systems, San Diego, CA, USA).

\section{Analysis of IgH and TCR Rearrangements}

Variable diversity junction (VDJ) rearrangements were amplified from peripheral blood DNA, using a set of three primers, in a seminested polymerase chain reaction (PCR). The IgH CDRIII region was amplified using a consensus variable heavy (VH) primer ( $5^{\prime}$ CTG TCG ACA CGG CCG TGT ATT ACT G $\left.3^{\prime}\right)$ with two consensus junction heavy (JH) primers (external primer: 5' ACC TGA GGA GAC GGT GAC C $3^{\prime}$ ), for the first round (30 cycles), nested primer $5^{\prime}$ ACC AGG GTC CCT TGG CCC CA $3^{\prime}$ for the second round (35 cycles). ${ }^{15}$ Both PCR reactions contained $0.2 \mu \mathrm{M}$ dinucleotide triphosphate (dNTP), $0.2 \mu \mathrm{M}$ of each primer, $1.5 \mathrm{mM} \mathrm{MgCl}_{2}$ and $1.5 \mathrm{U}$ Taq DNA polymerase (Q Biogen, Montréal, Québec, Canada). PCR products were visualized by a $12 \%$ polyacrylamide gel electrophoresis, stained with ethidium bromide. The FR2A region was amplified in a seminested PCR using the following primers: FR2A: 5' TGG (A/G) TG CG (CA) CAG (CG) C (T/C) 
(T/C) CN GG $3^{\prime}$, LJH : $5^{\prime}$ TGA GGA GAC GGT GAC C $3^{\prime}$, in a first 30-cycle round, and FR2A/VLJH : $5^{\prime}$ GTG ACC AGG GTN CCT TGG CCC CAG $3^{\prime}$ in a 20 -cycle reaction procedure with a 1:200 dilution of the first reaction. Amplified products (from 240 to $280 \mathrm{bp}$ ) were loaded on an $8 \%$ polyacrylamide gel. ${ }^{16}$ For the study of T-cell receptor $\gamma$ genes rearrangement, a one-step seminested PCR was performed using three primers. Two were directed against variable $\mathrm{V}$ regions, respectively, V $\gamma 11: 5^{\prime}$ TCT GG (G/A) GTC TAT TAC TGT GC $3^{\prime}$ and V $\gamma 101: 5^{\prime}$ CTC ACA CTC (C/T) CA CTT $3^{\prime}$, and one against the junction region. J $\gamma 11: 5^{\prime}$ CAA GTG TTG TTC CAC TGC TGC C $3^{\prime}$. The reaction's conditions followed the specifications described by McCarthy et al. ${ }^{17}$ Amplicons were stained with ethidium bromide on an $8 \%$ polyacrylamide gel electrophoresis. Fragments size ranged from 75 to $95 \mathrm{bp}$.

\section{Analysis of Bcl-2/IgH Rearrangements}

A nested PCR was used to detect $t(14 ; 18)$, with two sets of primers directed against the major breakpoint region (MBR) on chromosome 18, and the JH region on chromosome 14. The initial amplification was performed for 25 cycles using the MBR oligonucleotide $5^{\prime}$ CAG CCT TGA AAC ATT GAT GG $3^{\prime}$ and the $5^{\prime}$ ACC TGA GGA, GAC GGT GAC C $3^{\prime}$ nucleotide as $\mathrm{JH}$ consensus primer, with $1.5 \mu \mathrm{g}$ DNA template. In all, $5 \mu \mathrm{l}$ were used in the second-round PCR, for 30 cycles, using internal primers for MBR ( $5^{\prime}$ TAT GGT GGT TTG ACC TTT AG $3^{\prime}$ ) and the JH consensus region ( $5^{\prime}$ ACC AGG GTC CCT CCT TGG CCC CA $3^{\prime}$ ). Amplification was performed in the conditions described by Gribben et al. ${ }^{18}$ Size products ranged between 130 and $240 \mathrm{bp}$.

\section{Cytogenetics Analysis}

Peripheral blood cell suspensions from six out of eight patients were cultured at $37^{\circ} \mathrm{C}$ in RPMI 1640 (GIBCO, Grand Island, New York, NY, USA) supplemented with $20 \%$ fetal bovine serum, for $72 \mathrm{~h}$ with $2 \mathrm{ng} / \mathrm{ml}$ tetradecanoyl-o-phorbol-13-acetate. For two patients (cases 3 and 6), BM cells were cultured without mitogen. After processing the samples for the Q banding technique, ${ }^{19}$ karyotypes were described according to the International System for Human Cytogenetic Nomenclature (ISCN, 1995).

\section{Results}

\section{Hematological Data}

Eight patients (seven female and one male), median age 38 years (range $25-56$ years), were studied. The hematological characteristics of the patients are listed in Table 1. All patients were heavy smokers. Five out of eight presented with moderate splenomegaly, but none with hepatomegaly or adenomegaly. For all patients, a stable and polyclonal increase of serum IgM levels was observed (median $6 \mathrm{~g} / \mathrm{l}$; range 3.8-11.2). HLA-DR7 was found in two out of three tested patients. Median follow-up was 3.6 years (range 1-7 years). During this period, both the clinical course and hematological parameters were stable. All patients are still alive except for one who died in a car crash. One patient (case 3) developed a lung adenocarcinoma that was treated by surgery and radiotherapy, 6.5 years after the diagnosis of PPBL. None of the patients has developed any hematological malignancy so far.

Table 1 Clinical and biological characteristics of eight patients with PPBL

\begin{tabular}{|c|c|c|c|c|c|c|c|c|}
\hline & Case 1 & Case 2 & Case 3 & Case 4 & Case 5 & Case 6 & Case 7 & Case 8 \\
\hline Sex & Female & Female & Female & Female & Female & Male & Female & Female \\
\hline Age at diagnosis (years) & 45 & 32 & 37 & 38 & 25 & 34 & 40 & 56 \\
\hline Tobacco (pack/year) & 20 & 20 & 30 & 25 & 20 & 16 & 25 & 60 \\
\hline Clinical symptoms & Fatigue & Fatigue & None & None & Fatigue & Fatigue & None & None \\
\hline Splenomegaly (cm below costal margin) & $2 \mathrm{~cm}$ & $2 \mathrm{~cm}$ & $2 \mathrm{~cm}$ & $3 \mathrm{~cm}$ & $2 \mathrm{~cm}$ & Absence & Absence & Absence \\
\hline Hemoglobin (g/dl) & 12.9 & 11.8 & 13.9 & 12.3 & 13.7 & 14.4 & 13.8 & 12.4 \\
\hline Platelets (G/l) & 228 & 231 & 205 & 138 & 223 & 86 & 167 & 392 \\
\hline Leukocytes (G/l) & 19.8 & 4146 & 11.6 & 12.8 & 17.6 & 11.5 & 11.1 & 16.8 \\
\hline Lymphocytes (G/l) & 10.3 & 7.9 & 5.68 & 6.66 & 10 & 4.1 & 5.42 & 1.68 \\
\hline Binucleated lymphocytes (\%) & 5 & 1 & 2 & 8 & 3 & 19 & 2 & 25 \\
\hline Follow-up (years) & 5 & 5 & 7 & 2 & 7 & 1 & 1 & 1 \\
\hline IgM (g/l) (reference range: $0.4-2.4$ ) & 11.2 & 3.8 & 8.5 & 9.9 & 3.6 & 4.2 & 5.7 & 6 \\
\hline EBV EBER RNA & Neg & Neg & Neg & ND & Neg & Neg & ND & Neg \\
\hline HLA DR-7 & ND & ND & Neg & Pos & ND & Pos & ND & ND \\
\hline Cytogenetics & $47, \mathrm{XX},+3$ & $46, \mathrm{XX}$ & 46,XX & $46, \mathrm{XX}$ & $46, \mathrm{XX}$ & $46, X X$ & ND & del 6 \\
\hline IgH CDRIII, FR2A & ND & $\mathrm{P}$ & $\mathrm{P}$ & $\mathrm{P}$ & ND & $\mathrm{P}$ & $\mathrm{P}$ & OL \\
\hline TCR gamma & ND & $\mathrm{P}$ & $\mathrm{P}$ & $\mathrm{P}$ & ND & $\mathrm{P}$ & $\mathrm{P}$ & $\mathrm{P}$ \\
\hline $\mathrm{t}(14 ; 18) \mathrm{MBR}$, blood samples & ND & Neg & $1 \mathrm{R}$ & Neg & ND & $3 \mathrm{R}$ & $2 \mathrm{R}$ & $2 \mathrm{R}$ \\
\hline Bcl2 expression in BM & Pos & Pos & Pos & Pos & Pos & Pos & ND & Pos \\
\hline
\end{tabular}

P: polyclonal; OL: oligoclonal; ND: not done, R: rearrangement; Neg: negative; Pos: positive. 


\section{Peripheral Blood Cytology}

Lymphocytes were small-sized, with one, or less frequently two, round or ovoid nuclei. The proportion of binucleated lymphocytes varied between 1 and $25 \%$. The cytoplasm was moderately abundant, and basophilic. No membrane irregularity was observed (Figure 1g).

\section{BM Histology}

BM samples were obtained from seven out of eight patients. They were hypercellular (cases 4-6 and 8) or normocellular (cases 1-3). In all cases, hematopoietic tissue was infiltrated by a slight (cases 3 and 5) or moderate (cases 1, 2, 4, 6 and 8) intravascular and, at a lesser extent, interstitial lymphocytic pattern (Figure 1a, b). The intravascular pattern was difficult to recognize on stained sections (Figure 1a, b) that had to be screened carefully to identify lymphocytes arranged in chains within capillaries, or in small clusters within venous sinuses frequently distended by small lymphocytes. Immunohistochemistry provided important information for diagnosis, emphasizing the intravascular B-cell infiltrate (figure 1c-f). In all cases, immunohistochemistry revealed the interstitial lymphoid infiltrate to be composed of few T lymphocytes yet numerous B lymphocytes, and pointed out a peculiar prominent B-cell intravascular accumulation in cases with obvious infiltration (cases 1, 2, 4, 6 and 8) as well as in cases with questionable and minimal infiltration (cases 3 and 5). Clustered and lined Blymphoid cells were easily observed within the lumen of BM blood vessels and, at a lesser degree, in the interstitium, isolated and mixed up with other hematopoietic cells (Figure 1c, d). B-cell intravascular infiltration was confirmed by double immunostaining using anticollagen IV antibody for the basal membrane of medullary vessels and anti-CD20 antibody for intraluminal B-lymphocytes (Figure 1e, f). At high magnification, immunohistochemistry underlined the cytoplasmic details of B lymphocytes, revealed a few binucleated cells (Figure 1h) and showed sparse moderate anisocytosis for a minority of $\mathrm{B}$ lymphocytes (Figure 1j). B cells were negative for CD5, CD23 and CD43 antigens. There was a constant coexpression of the Bcl-2 antigen, consisting in an heterogeneous cytoplasmic staining of both binucleated and nonbinucleated lymphocytes with either a strong or discrete positivity, depending on the cells. In cases 2, 4 and 5, there were also a few hyperplastic centromedullary, lymphoid follicles surrounded by numerous Tlymphocytes and comprising a minority of centrofollicular B cells (Figure 1i). The reticulin network was normal (cases 2-5 and 8) or slightly increased (cases 1 and 6).

\section{EBV Detection}

No EBV associated small RNAs EBER was found by in situ hybridization in BM biopsies and none of the cases displayed EBV antigens by immunostaining in peripheral blood lymphocytes.

\section{Peripheral Blood Immunophenotyping}

Immunophenotyping details of peripheral blood lymphocytes showed that there was a majority of CD19+/CD22 + /CD79 + B cells in all patients. There was in some patients a residual subset of CD3 + T cells. However, B cells and binucleated lymphocytes never expressed CD3, CD5, CD10 or CD43. While surface IgG and IgA were absent, these cells were positive for surface IgM in six out of seven tested cases, and coexpressed IgD in three patients. Polyclonality was the rule. In six out of six tested cases, there was a definite expression of intracytoplasmic IgM in the majority of the cells. There was a consistent expression of FMC7 in six out of seven cases, weak expression of CD38 in three cases and CD11c positivity in three out of six cases. Adhesion molecules CD62E, CD62P and CD54 were never expressed except in case 2 for the latter. As shown in Table 2, there was a significantly lower expression of CD62L, CD11a, CD29, CD49d and CD31 in most cases tested except case 3, where cells displayed normal levels of these molecules.

Ki67 labeling only showed few positive cells, which was consistent with the near absence of cells in S or G2 phase in cell cycle analysis (means of 0.2 and $0.1 \%$, respectively) and thus indicated the absence of proliferation of peripheral lymphocytes.

\section{Elispot and High-resolution Immunoblot}

In Elispot, IgM-producing cells were up to 10 -fold higher than normal, while the proportions of IgG- and IgA-producing cells remained within normal range.

Consistently, a marked smear of IgM was observed in immunoblots without restriction, except in case 8 where $\mu / \lambda$ restriction was superimposed on the polyclonal smear. These bands confirmed the presence of B-cell oligoclonality in this patient shown by IgH CDRIII and FR2A analysis.

\section{Analysis of IgH, TCR $\gamma$ and Bcl-2/IgH Rearrangements (Figure 2)}

Seminested PCRs for IgH CDRIII and FR2a regions were performed in six cases and showed a polyclonal (cases 2-4, 6 and 7) or an oligoclonal population (case 8), while seminested PCR TCR $\gamma$ region analysis showed a polyclonal T-cell profile in all cases (Figure 2). MBR Bcl2-IgH rearrangements were detected in four out of six of PPBL cases with two amplified fragments of sizes of 120 and $210 \mathrm{bp}$ (case 6), 200 and $230 \mathrm{bp}$ (case 7), 120 and $200 \mathrm{bp}$ (case 8), one amplified fragment of $150 \mathrm{bp}$ (case 3), 

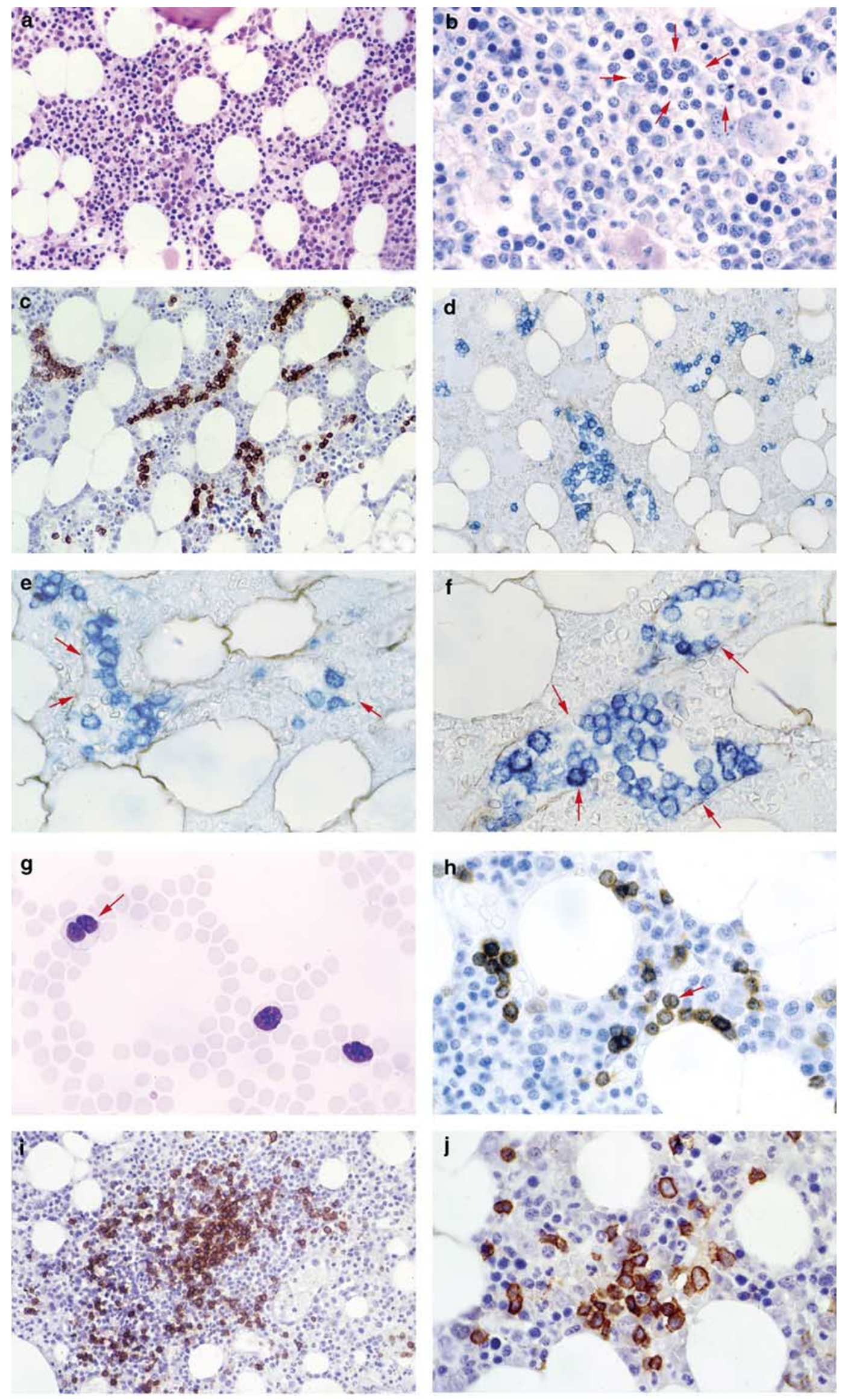
Table 2 Immunophenotypic data of adhesion molecules expression on lymphocytes from PPBL patients

\begin{tabular}{|c|c|c|c|c|c|c|c|c|c|}
\hline & Case 1 & Case 2 & Case 3 & Case 4 & Case 5 & Case 6 & Case 7 & Case 8 & Reference value ${ }^{9}$ \\
\hline CD62L & ND & 14500 & 34200 & 35000 & ND & 13900 & 14700 & 15400 & 23100 \\
\hline CD11a & ND & 14800 & 22500 & 14500 & ND & 18000 & 9600 & 7350 & 18500 \\
\hline CD29 & ND & 16500 & 15800 & 7200 & ND & 11800 & 10200 & 9000 & 11000 \\
\hline CD49d & ND & 13000 & 13000 & 10200 & ND & 9900 & 8400 & 7200 & 11400 \\
\hline CD31 & ND & 7800 & 13100 & 8400 & ND & 18000 & 0 & 5600 & 11700 \\
\hline
\end{tabular}

Figures in bold type indicate lowered levels. No CD31 expression was seen in case 7.

whereas there was no rearrangement in cases 2 and 4 .

\section{Cytogenetics Analysis}

Chromosomal analysis revealed an abnormal karyotype in two out of seven tested patients with acquired clonal trisomy 3 in one patient (case 1) and chromosome 6 deletion in another one (case 8).

\section{Discussion}

PPBL is a rare disorder of uncertain cause and less than 100 cases have been reported since 1982. In the present study, we report a new series of eight PPBL with special regard to morphological PPBL BM aspects. Very few reports have focused on PPBL BM samples, ${ }^{12}$ and when BM biopsy has been performed as part of the staging procedure, usually no relevant abnormalities were noted on morphological examination besides a slight medullary lymphocytosis, in some cases, consisting of small lymphoid aggregates. ${ }^{12}$ Here, BM infiltration was present in all of seven studied cases, consisting of an interstitial and particularly intravascular B-cell infiltration. The lesion, sometimes evasive on morphological examination, was constantly evidenced in immunohistochemistry, using B lineage antibodies that highlighted the B-cell lymphocytic infiltrate within biopsy specimens. This reactive Bcell infiltrate was however misleading, mimicking that observed in B lymphoproliferative malignant diseases, especially in splenic marginal lymphomas with or without villous lymphocytes. ${ }^{20-22}$

The histological diagnosis of PPBL was thus based on the detection of binucleated lymphocytes, presence of BM foci of anisocytic, activated
B lymphocytes-not found in small B-cell malignancies- and absence of nodules showing a germinal center and/or a marginal zone pattern, previously reported as a positive criterion for marginal zone lymphomas. ${ }^{23}$ In all of the reported cases, the BM B-cell infiltrate presented Bcl-2 intracytoplasmic positivity, but, conversely to B-small-cell lymphomas, Bcl-2 immunostaining was constantly heterogeneous.

This particular intravascular B-cell involvement, as well as the absence of adenomegaly could suggest an abnormality of leukocyte migration. There is increasing evidence that ICAM-1 and LFA-1 regulate cell-stroma and cell-cell interactions that are important for leukocyte migration and cell homing. ${ }^{23}$ Our observation of an altered expression of such adhesion molecules as CD62L, CD11c, CD29, CD49d and CD31 in most of the PPBL cases studied is consistent with this hypothesis. Interestingly, the pattern of adhesion molecules expression on PPBL is, in part, similar to what has been reported in B-cell CLL (24). Indeed, Nadkarni et $a l^{24}$ reported low-to-moderate expression of LFA-1 and negativeto-low expression of VLA-4 on PPBL, while ICAM-1 expression was observed only in patients with prominent lymphadenopathy. Altered migration could be responsible for the accumulation of lymphocytes in the BM and peripheral blood, as these $B$ cells would be unable to recirculate in secondary lymphoid organs. The hypothesis of the accumulation of a nonproliferating pool of B cells is also sustained by the absence of expression of Ki67 and low numbers of cells in S or G2 phase of the cell cycle.

This accumulation could also be related to apoptosis defaults as suggested recently by Roussel et $a .^{25}$ This would also be consistent with the expression of $\mathrm{Bcl} 2$, albeit heterogeneous, in all the

Figure 1 Peripheral blood and BM pathological aspects of PPBL. In peripheral blood, lymphocytes were small-sized, with one, or less frequently two (arrows), round or ovoid nuclei (g). Hematopoietic tissue was usually moderately infiltrated by PPBL. The intravascular pattern was difficult to recognize on sections stained with HES $(\mathbf{a}, \mathbf{b})$ that had to be screened carefully. Immunohistochemistry with antiCD20/L26 antibody provides important information for diagnosis emphasizing the intravascular B-cell infiltrate with clustered and lined B-lymphoid cells in sinusoids (c-f) and, at a lesser degree, isolated, mixed up with other hematopoietic cells (c,d). B-cell intravascular infiltration was confirmed by double immunostaining using anticollagen IV antibody for the basal membrane of medullary vessels (arrows) and anti-CD20 antibody for intraluminal B-lymphocytes (e,f). At high magnification, immunohistochemistry underlined the cytoplasmic details of B cells, revealed a few binucleated cells (h) (anti-CD79a antibody) and showed moderate anisocytosis in some places, for a minority of B lymphocytes (i, j) (anti-CD20/L26 antibody). 


\section{IgH CDRIII}

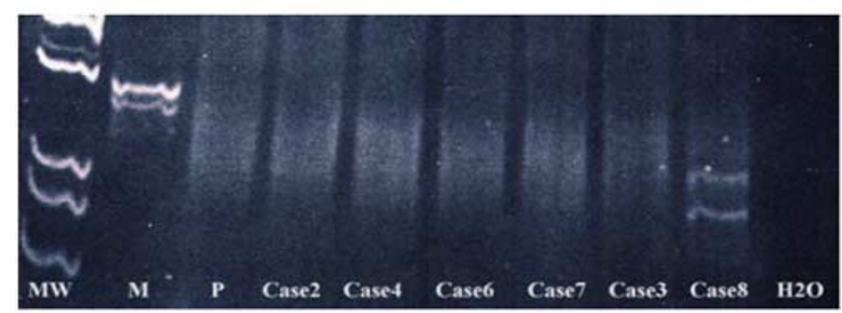

IgH FR2A

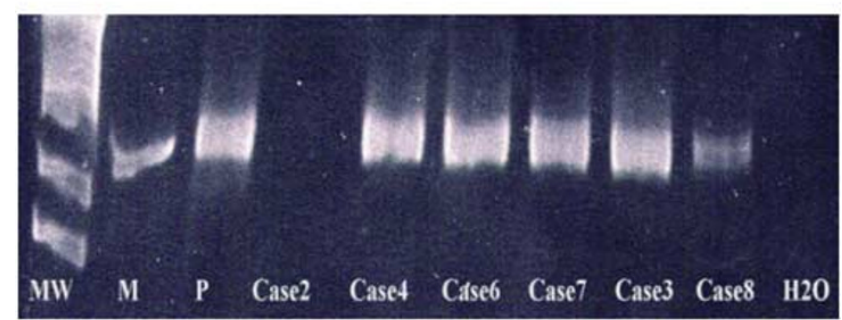

TCR gamma

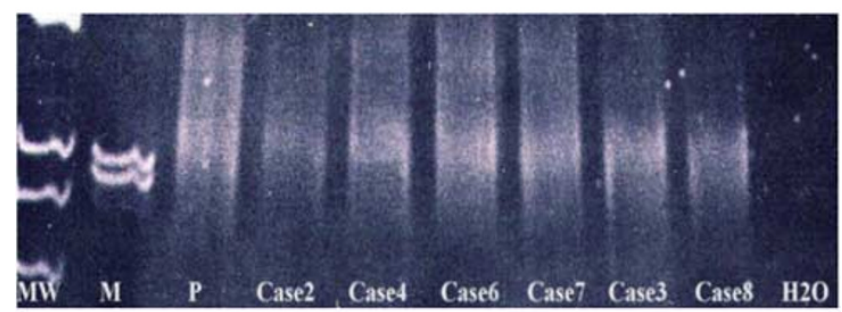

MBR Bcl2 Gene profile

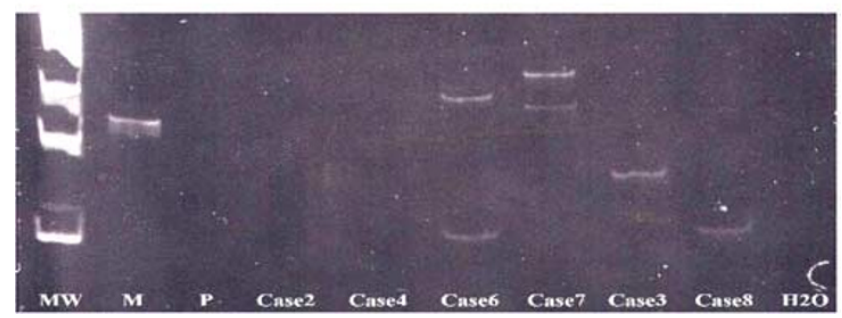

Figure 2 Analysis of IgH, TCR $\gamma$ and Bcl-2/IgH rearrangements. Seminested PCR for IgH CDRIII and FR2A shows a polyclonal (cases 2-4, 6 and 7) or an oligoclonal population (case 8), while seminested PCR TCR $\gamma$ region analysis showed a polyclonal T-cell profile in all cases tested. Nested PCR detected MBR Bcl-2/IgH rearrangements in $4 / 6$ of PPBL cases with two amplified fragments of 120 and $210 \mathrm{bp}$ (case 6), 200 and $230 \mathrm{bp}$ (case 7), 120 and $200 \mathrm{bp}$ (case 8), one amplified fragment of $150 \mathrm{bp}$ (case 3), whereas there was no rearrangement in cases 2 and 4.

cases reported here as well as in other studies. ${ }^{26}$ Lancry et $a l^{26}$ reported a $30 \%$ increase in the level of the Bcl-2-related antiapoptotic protein bcl-X in B cells from PPBL patients compared to controls.

PPBL misleading cytological and histological aspects are important to recognize, especially as this syndrome might represent a premalignant disease, although this notion still remains unclear. Although normal karyotypes were observed here in five patients, we observed one case of trisomy 3 , a chromosomal anomaly reported in a few cases of PPBL. ${ }^{27-29}$ We also observed a deletion of chromosome 6 in one case, as did Salcedo et al. ${ }^{29}$ However, the predominant chromosomal anomaly, the follicular lymphoma-associated $\mathrm{t}(14 ; 18)$ translocation has been reported in most of PPBL patients, ${ }^{30}$ including four out of the six patients tested in our series. Multiple Bcl-2/IgH gene rearrangements were present in most of the PPBL cases we report, indicating that an alteration of the B-cell population could result in the generation of several clones of $B$ cells carrying variants of the $t(14 ; 18)$. These genetic aberrations were found to be restricted to $\mathrm{B}$ cells (PPBL and normal lymphocytes), indicating the presence of a contrasting restricted cytogenetic population in PPBL patients. ${ }^{31}$ The long and indolent evolution in most patients showing multiple $t(14 ; 18)$ translocations confirms that this rearrangement is not sufficient to confer tumorigenicity, even though Bcl-2 is a well-recognized proto-oncogene. Among the cases reported in the literature, one patient developed a malignant pulmonary blastoma 11 years after diagnosis, ${ }^{32}$ another patient developed a large-cell lymphoma 19 years after initial PPBL diagnosis ${ }^{33}$ and one patient presented concomitantly polyclonal lymphocytosis and malignant gastric non-Hodgkin's lymphoma. ${ }^{31}$ With a 3.6 years follow-up, we did not observe any lymphoproliferative disease.

In our series, no clonal restriction was observed in peripheral blood lymphocytes in flow cytometry. Intracytoplasmic labeling and ELISPOT confirmed the predominance of IgM-secreting cells in the patients' peripheral blood. We observed a polyclonal IgH CDRIII and FR2A profile on PPBL-cells in five out of six patients. In the sixth case (case 8), this molecular study revealed an oligoclonal rearranged IgH profile both in the CDRIII and in the FR2A IgH sequences in two successive blood samples performed at 6 months interval (data not shown), which was confirmed by high-resolution immunoblot. These abnormalities could be part of a multi-step process beginning with the appearance of Bcl-2/IgH rearrangements and leading to the emergence of a malignant B lymphoproliferation. A monoclonal subpopulation has been reported in some PPBL patients as determined by analysis of IgH genes ${ }^{9,10}$ or chromosomal studies. ${ }^{27}$ The development of the complete syndrome probably relies on unidentified additional cofactors.

It has been speculated that PPBL results from an interaction of a genetic background with chronic nonspecific or antigenic stimulation, such as cigarette smoking or chronic viral infection. Smoking seems to play an important role since the majority of reported cases, including our series, involves heavy smokers. Hormonal influences could also be 
considered, since most of the cases reported are of women smokers. Yet, one of our patients was male.

Himmelman et $a l^{34}$ reported that PPBL could be an accumulation of memory IgD + CD27 + B cells, which was confirmed by Loembe et $a l^{35}$ who showed that these cells were not selected. These data suggest that chronic antigenic stimulation might play an important part in the pathogenesis of this disorder. It is possible that the persistence of $\operatorname{IgM}+/ \operatorname{IgD}+/ \mathrm{CD} 27+$ long-lived memory B cells developed in PPBL patients in response to antigenic stimulation might lead to the increased differentiation of cells carrying the $t(14 ; 18)$. However, we only observed $\operatorname{IgD}$ coexpression in three cases in our series, indicating, at variance with the report from Himmelman et $a l^{34}$ that IgD expression is not as systematic a feature as IgM expression, which remains the key characteristic of PPBL cells.

EBV was detected in the peripheral blood lymphocytes of some PPBL patients using PCR or fluorescent in situ hybridization (FISH) procedures $^{36}$ but this was not confirmed by others, including our own data. It therefore seems unlikely that EBV infection could be related with the immortalization of infected B cells as a pathophysiological hypothesis.

The pathophysiology of PPBL remains unclear and intriguing. PPBL presents features associated with true lymphomas such as genetic instability, multiple Bcl-2/IgH rearrangements and intravascular BM accumulation of IgM-producing Bcl-2+ cells. The occasional reports of oligoclonal and monoclonal Ig rearrangements in this disorder suggest that the polyclonal expansion may be followed by the emergence of a predominant clone. The absence of involvement of the spleen and lymph nodes, associated first with the marked accumulation of B cells not only in peripheral blood but also in BM blood vessels and second with the absence of proliferation features, suggest that this abnormal persistent population of B cells is somewhat trapped in blood vessels. This could be well explained by the alteration of adhesion molecules, reported in this study, yielding the peculiar and misleading BM histology we describe.

In any case, the benign indolent clinical course and the lack of biological evolution in the majority of PPBL cases imply that it is mandatory to distinguish this disorder from true malignant lymphoproliferative disorders, so that aggressive therapy should be avoided for PPBL patients.

\section{Acknowledgements}

The authors thank Corinne Bonnet, Agnès Collet, Yolande Lagappe, Marie-Pierre Pletagut, Arlette Raoul, Eve Nowak, Muriel Anfige and Claire Bossège for excellent technical assistance and Sylviane Pizzagali for molecular analysis (Department of Pathology, Nancy University Hospital).

\section{References}

1 Hamblin TJ. Achieving optimal outcomes in chronic lymphocytic leukaemia. Drugs 2001;61:593-611.

2 Wilkinson LS, Tang A, Gjedsted A. Marked lymphocytosis suggesting chronic lymphocytic leukemia in three patients with hyposplenism. Am J Med 1983;75:1053-1056.

3 Berthelot JM, Bataille R, Maugars Y, et al. Rheumatoid arthritis as a bone marrow disorder. Semin Arthritis Rheum 1996;26:505-514.

4 Marti GE, Ryan ET, Papadopoulos NM, et al. Polyclonal B-cell lymphocytosis and hypergammaglobulinemia in patients with Gaucher disease. Am J Hematol 1988;29:189-194.

5 Gordon DS, Jones BM, Browning SW, et al. Persistent polyclonal lymphocytosis of B lymphocytes. N Engl J Med 1982;307:232-236.

6 Troussard X, Valensi F, Debert C, et al. Persistent polyclonal lymphocytosis with binucleated B lymphocytes: a genetic predisposition. $\mathrm{Br} \mathrm{J}$ Haematol 1994;88:275-280.

7 Carr R, Fishlock K, Matutes E. Persistent polyclonal B-cell lymphocytosis in identical twins. Br J Haematol 1997;96:272-274.

8 Delage R, Jacques L, Massinga-Loembe $\mathrm{M}$, et al. Persistent polyclonal B-cell lymphocytosis: further evidence for a genetic disorder associated with B-cell abnormalities. Br J Haematol 2001;114:666-670.

9 Delage R, Darveau A, Jacques L, et al. Chronic B cell lymphocytosis of the young woman: clinical, phenotypic and molecular studies in 5 cases. Blood 1992;80(Suppl 1):447a (abstract).

10 Chan MA, Benedict SH, Carstairs KC, et al. Expansion of B lymphocytes with an unusual immunoglobulin rearrangement associated with atypical lymphocytosis and cigarette smoking. Am J Respir Cell Mol Biol 1990;2:549-552.

11 Mossafa H, Troussard X, Valensi F, et al. Isochromosome $\mathrm{i}(3 \mathrm{q})$ and premature chromosome condensation are recurrent findings in chronic B-cell lymphocytosis with binucleate lymphocytes. Leuk Lymphoma 1996;20:267-273.

12 Perreault C, Boileau J, Gyger M, et al. Chronic B-cell lymphocytosis. Eur J Hematol 1989;42:361-367.

13 Kennel-De March A, Béné MC, Renoult E, et al. Low levels of spontaneously activated peripheral IgAsecreting cells in non transplanted IgA nephropathy patients. Am J Kidney Dis 1997;30:64-70.

14 Dean PN, Jett JH. Mathematical analysis of DNA distributions derived from flow microfluorometry. J Cell Biol 1974;60:523-527.

15 Delabie J, Tierens A, Wu G, et al. Lymphocyte predominance Hodgkin's disease: lineage and clonality determination using a single-cell assay. Blood 1994;84:3291-3298.

16 Diss TC, Peng H, Wotherspoon AC, et al. Detection of monoclonality in low-grade B-cell lymphomas using the polymerase chain reaction is dependent on primer selection and lymphoma type. J Pathol 1993;169: 291-295.

17 McCarthy KP, Sloane JP, Kabarowski JH, et al. A simplified method for the detection of clonal rearrangements of the T-cell receptor-gamma chain gene. Diagn Mol Pathol 1992;1:173-179.

18 Gribben JG, Freedman AS, Woo SD, et al. All advanced stage non-Hodgkin's lymphomas with a polymerase 
chain reaction amplifiable breakpoint of bcl-2 have residual cells containing the bcl-2 rearrangement at evaluation and after treatment. Blood 1991;78: 3275-3280.

19 Caspersson T, Zech L, Johansson C, et al. Identification of human chromosomes by DNA-binding fluorescent agents. Chromosoma 1970;30:215-227.

20 Franco V, Florena Ada Maria , Lannitto E. Splenic marginal zone lymphoma. Blood 2003;101:2464-2472.

21 Labouyrie E, Marit G, Vial J-P, et al. Intrasinusoidal bone marrow involvement by splenic lymphoma with villous lymphocytes: a helpful immunohistologic feature. Mod Pathol 1997;10:1015-1020.

22 Audouin J, Le Tourneau A, Molina T, et al. Patterns of bone marrow involvement in 58 patients presenting primary splenic marginal zone lymphoma with or without circulating villous lymphocytes. Br J Haematol 2003;122:404-412.

23 Milicevic NM, Milicevic Z, Westermann J. Lymphocyte function-associated antigen-1 and intercellular adhesion molecule-1 expression on B-cell subsets and the effect of splenectomy-experimental studies. Leuk Lymphoma 2002;43:2071-2074.

24 Nadkarni JJ, Perambakam SM, Rathore V-B, et al. Expression of adhesion molecules in B-cell chronic lymphocytic leukaemia: an analysis in lymphoid compartments: peripheral blood, bone marrow and lymph node. Cancer Biother Radiopharm 1998;4: 269-274.

25 Roussel M, Roue G, Sola B, et al. Dysfunction of the Fas apoptotic signaling pathway in persistent polyclonal B-cell lymphocytosis. Haematologica 2003;88:239-240.

26 Lancry L, Roulland S, Roue G, et al. No BCL-2 protein over expression but BCL-2/IgH rearrangements in $\mathrm{B}$ cells of patients with persistent polyclonal B-cell lymphocytosis. Hematol J 2001;2:228-233.

27 Mossafa H, Malaure H, Maynadie M, et al. Persistent polyclonal B lymphocytosis with binucleated lympho- cytes: a study of 25 cases. Groupe Français d'Hématologie Cellulaire. Br J Haematol 1999;104:486-493.

28 Samson T, Mossafa H, Lusina D, et al. Dicentric chromosome 3 associated with binucleated lymphocytes in atypical B-cell chronic lymphoproliferative disorder. Leuk Lymphoma 2002;43:1749-1754.

29 Salcedo I, Campos-Caro A, Sampalo A, et al. Persistent polyclonal B lymphocytosis: an expansion of cells showing IgVH gene mutations and phenotypic features of normal lymphocytes from the CD27+ marginal zone B-cell compartment. Br J Haematol 2002;116:662-666.

30 Delage R, Roy J, Jacques L, et al. All patients with persistent polyclonal B cell lymphocytosis present Bcl-2/Ig gene rearrangements. Leuk Lymphoma 1998;31:567-574.

31 Callet-Bauchu E, Renard N, Gazzo S, et al. Distribution of the cytogenetic abnormality $+\mathrm{i}(3)(\mathrm{q} 10)$ in persistent polyclonal B-cell lymphocytosis: a FICTION study in three cases. Br J Haematol 1997;99:531-536.

32 Lawlor E, Murray M, O’Briain DS, et al. Persistent polyclonal B lymphocytosis with Epstein-Barr virus antibodies and subsequent malignant pulmonary blastoma. J Clin Pathol 1991;44:341-342.

33 Roy J, Ryckman C, Bernier V, et al. Large cell lymphoma complicating persistent polyclonal B cell lymphocytosis. Leukemia 1998;12:1026-1030.

34 Himmelmann A, Gautschi O, Nawrath $\mathrm{M}$, et al. Persistent polyclonal B-cell lymphocytosis is an expansion of functional $\operatorname{IgD}(+) \mathrm{CD} 27(+)$ memory $\mathrm{B}$ cells. Br J Haematol 2001;114:400-405.

35 Loembe MM, Neron S, Delage R, et al. Analysis of expressed V(H) genes in persistent polyclonal B cell lymphocytosis reveals absence of selection in CD27+IgM+IgD+ memory B cells. Eur J Immunol 2002;32:3678-3688.

36 Mitterer M, Pescosta N, Fend F, et al. Chronic active Epstein-Barr virus disease in a case of persistent polyclonal B-cell lymphocytosis. $\mathrm{Br} \mathrm{J}$ Haematol 1995;90:526-531. 